\title{
3D Numerical Simulation of Shield Tunnel Subjected to Swelling Effect Considering the Nonlinearity of Joint Bending Stiffness
}

\author{
Qixiang Yan' ${ }^{1}$ Chuan Zhang ${ }^{1}$,, Wang Wu'1, Hongxue Zhu³, Wenbo Yang ${ }^{1 *}$ \\ ${ }^{1}$ Key Laboratory of Transportation Tunnel Engineering, Ministry of Education, \\ Southwest Jiaotong University, Chengdu, 610031, China \\ 2 Smart Material and Structure Laboratory, Department of Mechanical Engineering, \\ University of Houston, Houston, TX 77204, USA \\ ${ }^{3}$ China Construction Underground Space Co., Ltd, \\ Chengdu, 610073, China \\ *Corresponding author, e-mail: yangwenbo1179@hotmail.com
}

Received: 09 March 2019, Accepted: 23 May 2019, Published online: 17 June 2019

\begin{abstract}
In this paper, the authors developed a three dimensional shell-spring numerical model of a shield tunnel, in which the elastic shell elements were adopted to model the segments and the spring models were used for the simulation of the segmental joints. The highlight of this research is that the non-linearity of the joint bending stiffness was taken into consideration, which was first determined through the numerical simulation by using a refined 3D continuum model of the segment-joint structure. The automatic iteration of the joint bending stiffness was achieved through programming with the ANSYS ADPL software. Based on a specific engineering example, a 3D continuum-shell-spring model was established to analyze the internal forces of shield tunnel segmental linings subject to swelling soils. The developed numerical model and its application in the analysis of the internal forces of shield tunnel segmental linings in swelling ground will provide useful reference and guidance for the numerical calculation in similar engineering projects in future.
\end{abstract}

\section{Keywords}

numerical modelling, swelling ground, shield tunnel, joint bending stiffness, non-linearity

\section{Introduction}

Swelling ground is a rock or soil material that predominantly contains the clay mineral montmorillonite sensitive to natural moisture content changes and has a potential to experience significant volume increment associated with increasing in moisture content [1], the volume of some swelling rocks or soils increases up to thirty percent or even more due to an increase in natural water contents [2-4]. This increase may lead to serious damages to building and civil engineering structures, particularly those underground structures such as tunnels. Engineering problems caused by swelling ground during the construction and long-term use of tunnels have been reported in numerous case studies [5-8], as exhibited in Fig. 1. Therefore, studies in terms of the swelling effect on tunnel structures are of great significance to better design, construction and maintenance of tunnelling in swelling ground.
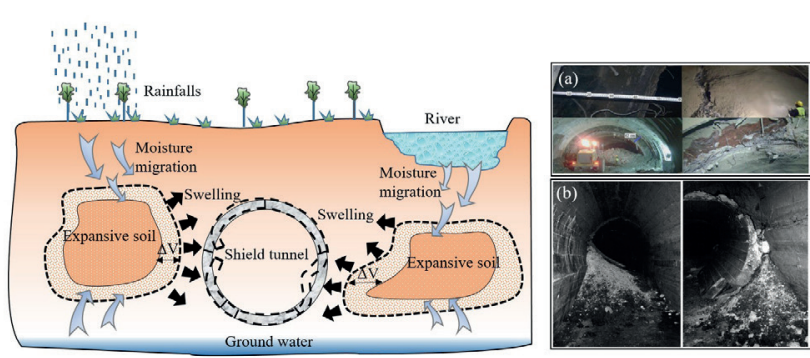

Fig. 1 Swelling ground affecting tunnel structures: (a) Deformations of supports in T13 tunnel, Turkey; (b) Damage to concrete linings in Caneva-Stevenà Quarry Tunnel, Italy

Through theoretical and experimental methods, numbers of researches have been carried out on tunnelling in swelling ground. Among them, many studies focus on the swelling strain and pressure, especially the prediction of the long-term deformation of the swelling soils or rocks [9-12]. 
However, the influence of the swelling strain on tunnel linings receives very little attention, even less attention in terms of the effects on shield tunnels.

From the literatures with respect to the analysis of the internal forces of shield tunnel segmental linings subject to the swelling effect, it can be seen that the numerical modelling still plays a major role by using the finite element method (FEM). This is mainly attributed to the fact that the swelling properties of the expansive soil are very hard to be accurately controlled to meet the designed experiment requirements, therefore, making it difficult to study on this topic through physical modelling experiments. In addition, currently, there are very few reports about the in-situ monitoring on the internal forces of tunnel linings under the swelling effect. Through the numerical modelling, Wang et al built a two-dimensional (2D) load-structure model for the structural numerical analysis of the mechanical behaviors of shield tunnel linings [13]. Similarly, Fang et al adopted the same model to study the axial forces and bending moments of shield tunnel linings affected by expansive soils underlying sandy pebble layers [14]. Seifabad et al. [15] studied the swelling behaviors in a tunnel excavated through rocks by using a 2D finite element modeling method. Aforementioned researches indicate that the 2D load-structure models were most commonly used, in which the specialized beam and spring elements were used for the simulation of shield tunnel linings while the Winkler type springs were used to represent the response from the swelling ground. Meanwhile, there are few reports in relation to the use of $3 \mathrm{D}$ continuum models for the shield tunnel linings subject to the swelling soils, in spite that extensive applications have been found in the refined 3D continuum models for the segmental linings [16-19]. Clearly, the first approach is less computationally demanding than the 3D continuum modelling. However, the modelling of the segmental linings by beams can hardly reflect the 3D structural stress state, since the segment rings of shield tunnels are longitudinally connected through the stagger-jointed assembling in practice. In addition, the simulation of soils by springs may suffer from the lack of physical significances, particularly in the case of expansive soils, in which this problem can be significantly non-linear. At present, no reliable approach has been developed to define the constitutive relationship of spring models for the simulation of soil's swelling behaviors [20]. On the other hand, the refined 3D numerical modelling cannot easily meet practical and computational demands due to difficulties in sophisticated and accurate numerical modelling for both the complex swelling phenomenon and structural discontinuities of shield tunnel linings.
Therefore, in this paper, the authors developed a 3D ground-structure model, in which the 3D continuum approach was adopted to model swelling soils and a 3D shell-spring model was used for the simulation of segmental linings. Specifically, the swelling effect induced by ground moisture increments was modeled by the thermal expansion. Furthermore, the current researches show that the bending stiffness of the segmental joints, which has obvious non-linear characteristics, is directly related to the corresponding axial forces and bending moments. This has great influence on the calculation of the internal forces of the lining structures. Thus, in order to better simulate the real stress states of the lining structures, the corresponding bending stiffness of joint bolts under different axial forces and bending moments was taken into consideration. The automatic iterative process in the numerical calculation was achieved, which is the highlight of this paper. Based on the proposed ground-shell-spring model, the numerical analysis of the internal forces of the segmental linings subject to the swelling effect was performed.

\section{Numerical calculation of the non-linear bending stiffness of segmental joints}

In practice, the non-uniform distribution of axial forces and bending moments along the lining ring leads to significant differences in the joint bending stiffness. In this section, a sophisticated 3D continuum model for a local segment-joint structure was established. The non-linear joint bending stiffness under different axial forces and bending moments was obtained through the FEM method, which would provide essential data for the subsequent iteration of the non-linear joint bending stiffness in the shell-spring shield tunnel model.

Since geometrically accurate modelling of segments requires too much meshing and computational resources, and the material properties and contact relationships show clear non-linear characteristics, therefore the following assumptions were made: (1) the segment concrete material is regarded as a single and homogeneous material with ideal elasticity, and the reinforcing steel bars inside the concrete are ignored. (2) The influence of the geometry shape of the capping segment is considered negligible, the geometric size of the standard segment is adopted for the simulation. (3) The connection structure between the two adjacent segments is simplified as a straight and flat structure. (4) The embedded PVC sleeve component in the bolt hole is also ignored, hence, the bolt has direct squeezing and sliding contact with the concrete. 


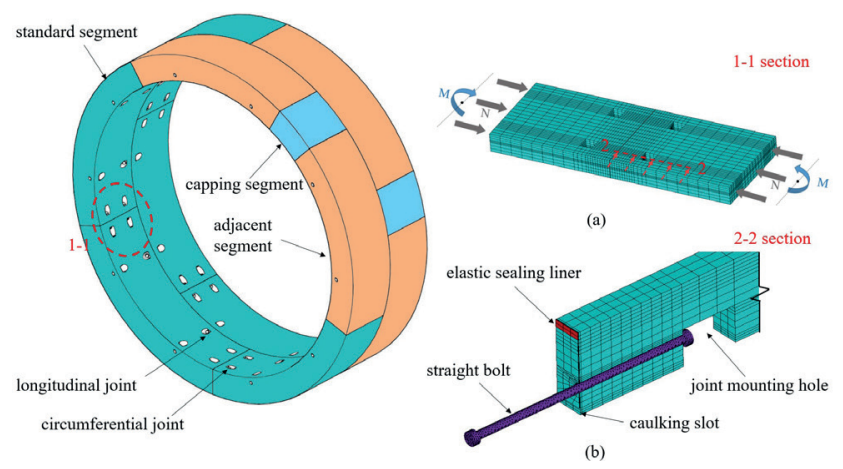

Fig. 2 Segment-joint model: (a) Finite element model of the local segment-joint structure; (b) 2-2 cross-section view

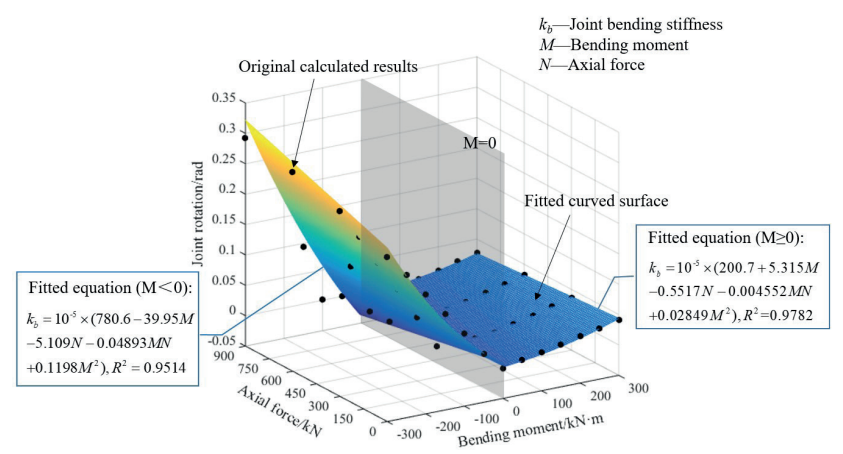

Fig. 3 Relationship among the joint rotation angle, axial force and bending moment

\subsection{Numerical model of segmental joints}

The segment-bolt joint model is shown in Fig. 2. The solid element solid45 in ANSYS was adopted to model the segmental lining. The value of the axial force is set to $0 \mathrm{kN}$, $200 \mathrm{kN}, 400 \mathrm{kN}$ and $800 \mathrm{kN}$ and $1000 \mathrm{kN}$, respectively. The value of the bending moment is set to $0 \mathrm{kN} \cdot \mathrm{m}, \pm 50 \mathrm{kN} \cdot \mathrm{m}$, $\pm 100 \mathrm{kN} \cdot \mathrm{m}, \pm 150 \mathrm{kN} \cdot \mathrm{m}, \pm 200 \mathrm{kN} \cdot \mathrm{m}, \pm 250 \mathrm{kN} \cdot \mathrm{m}$ and $\pm 300 \mathrm{kN} \cdot \mathrm{m}$, respectively. In addition, the length, width and thickness of the straight segment are $2.0 \mathrm{~m}, 1.5 \mathrm{~m}$ and $0.3 \mathrm{~m}$, respectively. There are two bolt holes set on each end of the segment. The bolt was modeled by the solid element solid92. The diameter and length of the straight cylindrical bolt are $28.0 \mathrm{~mm}$ and $400.0 \mathrm{~mm}$, respectively. The diameter of the nut is $50.0 \mathrm{~mm}$, and the diameter of the bolt hole is $34.0 \mathrm{~mm}$. Additionally, the MooneyRivlin elastic constitutive model was adopted to simulate the wmechanical behaviors of the elastic sealing liner, in which the two controlled parameters of the rubber material with the Shore hardness of 40 degrees, namely, C10 and $\mathrm{C} 01$ are $0.195 \mathrm{MPa}$ and $0.0162 \mathrm{MPa}$. Moreover, the boundary is restrained against its vertical displacements.

The joint bolt pre-tension was also considered due to the fact that the bolt always needs to be pre-stressed after its placement and installation. In numerical simulation, since the pre-loading elements cannot be used to transfer shearing forces, and the shearing deformation will easily lead to the non-convergence of calculation. Therefore, in this part, the simulation of the bolt pretension was achieved by lowering the bolt's temperature while keeping the other components' temperature constant, thus making the bolt itself contract and then generate the pre-tightening force. Through the mathematical conversion, the bolt pre-tightening loading could be obtained. The pre-tightening force was set to $100 \mathrm{kN}$ in this part. Details see Appendix 1.

\subsection{Calculation results}

Through the numerical simulation, the results of joint rotation angles under different axial forces and bending moments were obtained. Based on that, the fitted curved surface of the calculated data and the piecewise fitted equations were displayed in Fig. 3. The joint bending stiffness is the reciprocal of the slope of the curved surface. It can be seen from the figure that the bending moment has larger influences on the joint rotation angle while the effect of the axial force is relatively limited. The bending moment has a positive correlation with the angle. With the increasing of the bending moment, there is an upward trend of the joint rotation angle, and the trend becomes sharper especially under the negative bending moment. Additionally, when the bending moment is constant, the larger the axial force, the smaller the rotation angle of the joint.

\section{Numerical modelling of shield tunnel structures}

The 3D shell-spring model is essentially an extension of the $2 \mathrm{D}$ beam-spring model in the longitudinal direction of tunnels. It inherits the advantage of the beam-spring model in the computational efficiency, and can comprehensively consider the influences of different factors on the mechanical behaviors of segmental lining joints. Particularly after introducing the iteration of the non-linearity of the joint bending stiffness, it is also capable of avoiding the defect that the $2 \mathrm{D}$ beam-spring model cannot fully simulate the complex non-linear flexural performances of segmental lining joints. In addition, the longitudinal bending moment distribution of each segment ring in the shield tunnel can be clearly exhibited.

\subsection{Basic assumption}

In the numerical simulation of the shield tunnel lining, the following assumptions were made: (1) the axial pressure at the joint between two adjacent circular segments is borne by the concrete and the bolt, while the axial tension is only 
borne by the bolt; (2) the shear stress at the joint is also borne together by the concrete and the bolt, and the shearing stiffness is distributed evenly on the joint surface; (3) the bending moment at the joint is merely borne by the joint bolt, and the bending stiffness is distributed evenly on the joint surface; (4) the bending moment along the tunnel longitudinal direction is borne both by the concrete and the bolt.

\subsection{Geometric parameters}

The shield tunnel was modelled on the basis of the typical segmental ring of the tunnel prototype in the Chengdu Metro Line. As shown in Fig. 4, the outer diameter is $6.0 \mathrm{~m}$, and the lining width and thickness are $1.5 \mathrm{~m}$ and $0.3 \mathrm{~m}$, respectively. The standard C50 concrete with its compressive strength larger than $50.0 \mathrm{Mpa}$ is adopted for the shield tunnel lining. Each segmental ring is assembled by 6 circular arc blocks, including one capping block, two adjacent blocks and three standard blocks, with corresponding central angles of $15.0^{\circ}, 64.5^{\circ}$ and $72.0^{\circ}$, respectively. In addition, the segments are connected by straight cylindrical bolts with the diameter of $24.0 \mathrm{~mm}$ and the length of $400.0 \mathrm{~mm}$ in both the circumferential and longitudinal directions. A total number of 12 bolts are used for 6 joints in each lining ring, evenly arranged every $36^{\circ}$ of central angle along the circumferential direction, and 10 longitudinal bolts are used in each ring. In the assembling of segments, in order to enhance the structural stiffness of the shield tunnel, all the rings are connected through the stagger-joint assembling, which is achieved by rotating the central angle of the adjacent ring by $180^{\circ}$ along the tunnelling direction.

\subsection{Segmental lining model}

The tunnel lining was modelled by the shell element shell63, with its thickness being set to $0.3 \mathrm{~m}$. According to the Chinese Design Code of the Reinforced Concrete, the C50 reinforced concrete has an elastic modulus of $34.5 \mathrm{Gpa}$ and a Poisson's ratio of 0.2 , and its unit weight equals $26 \mathrm{kN} / \mathrm{m}^{3}$. The geometric parameters of the segment were exactly determined according to the tunnel prototype in the Chengdu Metro Line. Each lining ring model consists of 10 shell element rings. Besides, the stagger-joint assembling was also taken into consideration. It should be noted that the single segment model is independent of each other, which means that although the shell element nodes and curves among segment models share the same spatial position, however, they do not directly transmit any stress or deformation.

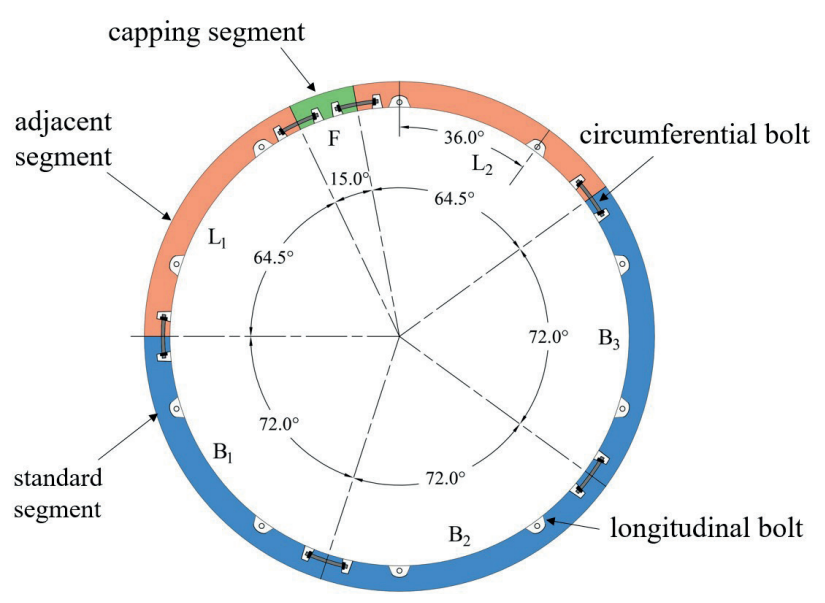

Fig. 4 Segmental lining structure prototype

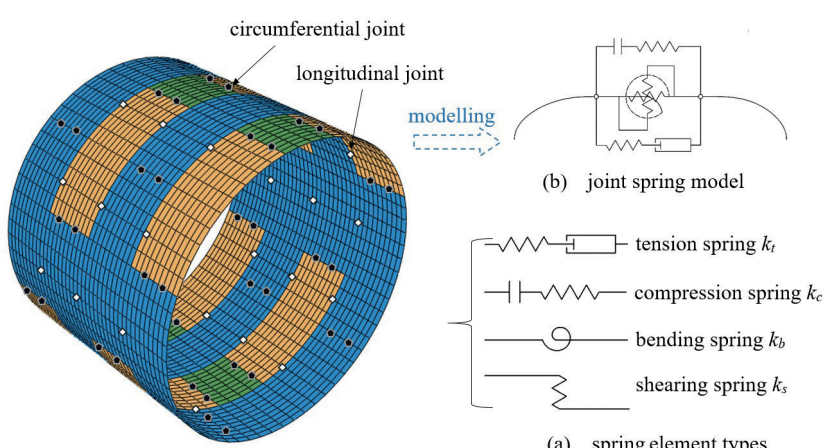

Fig. 5 Shield tunnel model: (a) 4 different types of spring models; (b) Single spring joint model

\subsection{Joint model}

The segmental joint was simulated by a group of different spring models, and each spring was modelled by the specific element in ANSYS. Three elements including the link10, combin39 and combin14 were employed to simulate the compression and tension, bending and shearing effects on the joint, respectively. Each joint was modelled by a total of five different types of spring models, namely, the compression spring, tension spring, radial shearing spring, tangential shearing spring and bending spring. A total of 12 circumferential joint models and 10 longitudinal joint models are used in each ring. The entire shield tunnel model consists of 4 segmental rings, as depicted in Fig. 5.

Moreover, the stiffness value of each spring in the joint model needs to be set according to the geometric and mechanical parameters of the joint prototype. With increasing of the external loadings, the axial and shearing stiffness of the connection joint exhibit non-linear characteristics to a certain degree. However, its influence on the structural internal forces has been testified to be negligible in some studies [21, 22]. Hence, both the axial stiffness and the shearing stiffness were taken as constant values in this part. 
The stiffness of the compression spring (written as $k_{c}$ ) is calculated according to the joint face area and the mechanical properties of the concrete material. Similarly, the spring tensile stiffness $\left(k_{t}\right)$ is obtained on the basis of the cross cross-sectional area and the mechanical properties of the bolt material. As mentioned before, both the compression and tension springs were modelled by the link10 element, whose length and cross-sectional area are set to $150.0 \mathrm{~mm}$ and $1000 \mathrm{~mm}^{2}$, respectively. The elastic moduli of the concrete and bolt are respectively $34.5 \mathrm{GPa}$ and $210 \mathrm{GPa}$. It can be easily calculated that the contact area between two adjacent segmental rings along the longitudinal direction and that between two adjacent circumferential segments are $5.37 \mathrm{~m}^{2}$ and $0.45 \mathrm{~m}^{2}$, respectively. Based on Eqs. (1) and (2), the compression spring stiffness in each single longitudinal joint model equals $1.24 \times 10^{8} \mathrm{kN} \cdot \mathrm{m}^{-1}$, while the value in each single circumferential joint model equals $0.52 \times 10^{8} \mathrm{kN} \cdot \mathrm{m}^{-1}$. The tension spring stiffness in both longitudinal and circumferential joint models shares the same value, being equal to $0.95 \times 106 \mathrm{kN} \cdot \mathrm{m}^{-1}$.

$k_{c}=\frac{E_{c} A_{c}}{N l_{c}}$,

$k_{t}=\frac{E_{b} A_{b}}{l_{b}}$,

where $E_{c}$ and $E_{b}$ denote the elastic modulus of the concrete and bolt materials, respectively. $A_{c}$ and $A_{b}$ represent the area of the longitudinal joint face and the cross-sectional area of the bolt, respectively. $N$ represents the number of the compression springs. $l_{c}$ is the length of each spring, and $l_{b}$ is the length of the bolt.

In addition, both the radial and tangential shearing springs have the same value of the shearing stiffness (denoted as $k_{s}$ ), which can be acquired as follows:

$k_{s}=\frac{1}{n}\left[\frac{3 E I}{(0.5 L)^{3}}+\frac{G_{b} A_{b}}{e l}\right]$,

where $E$ is the elastic modulus of the segment, and $I$ is the cross-sectional moment of inertia of the segment. $L$ and $l$ represent the lengths of the segment and the connection bolt, respectively. $G_{b}$ is the shearing modulus of the bolt, $A_{b}$ is the cross-sectional area of the bolt, and $e$ stands for the shape coefficient of the segment section $(e=0.9) . n$ is the total number of the radial or tangential shearing springs.

Based on Eq. (3), the shearing stiffness value of each radial or tangential shearing spring in the longitudinal joint model is $0.18 \times 10^{6} \mathrm{kN} \cdot \mathrm{m}^{-1}$, which is considered to be equal to that in the circumferential joint model.

\subsection{Segmental lining model}

In view of the significant influence of the non-linear characteristics of the joint bending stiffness on the structural internal forces of tunnel linings, the iteration of the nonlinear joint bending stiffness can effectively improve the accuracy of the numerical model. The basic principle is that the bending stiffness value needs to be adjusted in real time during the iteration process based on the updated feedback from the joint stress states. The stiffness value was determined according to the relationship among the joint rotation angle, axial force and bending moment in the aforementioned content.

The iteration was achieved through the secondary development and programming in ANSYS ADPL language. Basically, there are three major procedures in the entire process: (a) Firstly, during the establishment of the numerical model, an initial value of the joint bending stiffness needs to be set, and then the computation starts. (b) Secondly, according to the calculated results of the internal forces at the joints, the stiffness value is updated based on the relationship among the joint rotation angle, axial force and bending moment. (c) Finally, not until is the stiffness value close to the updated value in the last step within an allowable range, the iteration process ends and the final results can be obtained, otherwise, the iteration continues to cycle. The procedure of the iteration is shown in Fig. 6, where $k_{b}^{0}$ represents the initial value of the joint bending stiffness, and it is determined under the condition of $M_{0}=0 \mathrm{kN} \cdot \mathrm{m}$, $N_{0}=0 \mathrm{kN}$. i represents the cumulative number of iterations, $\varepsilon$ is the threshold value of the convergence, and $\varepsilon=1 \%$.

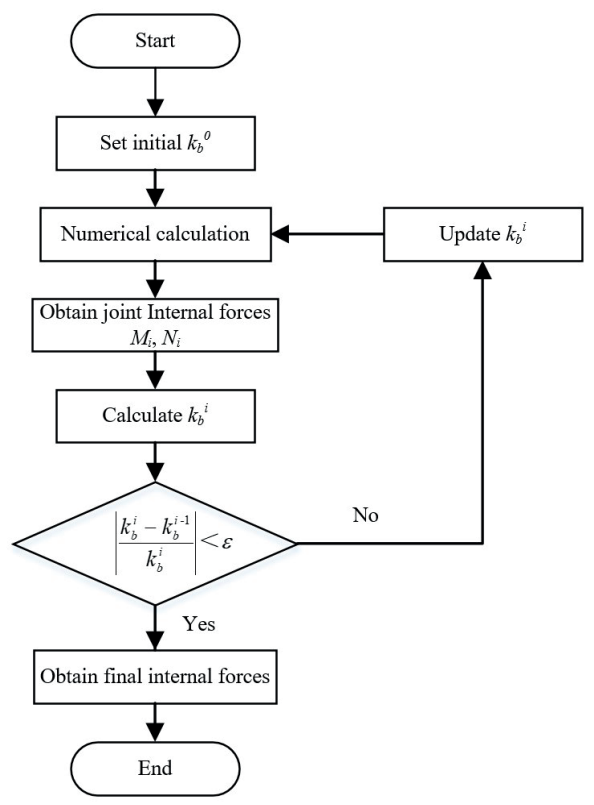

Fig. 6 Flow chart of the iteration process 
It should be noted that the iteration was merely performed aimed at the non-linear stiffness of the bending spring at the circumferential joint. Although the bending spring was set at the longitudinal joint as well, the stratigraphic loadings were considered to be distributed evenly along the tunnelling direction, which makes the bending effect on the longitudinal joint neglected. Currently, there are few reliable theoretical or empirical equations referring to the calculation of the bending stiffness of the circumferential or longitudinal joints, and the bending stiffness was generally determined by the model test or numerical simulation in most cases. According to the experiments conducted by Feng et al. [23], the bending stiffness of the joint in typical metro shield tunnel approximately ranges from $3.0 \times 104 \mathrm{kN} \cdot \mathrm{m} \cdot \mathrm{rad}^{-1}$ to $1.8 \times 105 \mathrm{kN} \cdot \mathrm{m} \cdot \mathrm{rad}^{-1}$. Therefore, in this part, the stiffness of the bending spring at the longitudinal joint model was set to a fixed value of $1.5 \times 105 \mathrm{kN} \cdot \mathrm{m} \cdot \mathrm{rad}^{-1}$.

\section{Numerical modelling of the swelling ground}

According to the related researches, the gravimetric moisture content change is considered as the soil swelling strain driver in the modelling of the swelling behavior [24, 25]. The swelling behavior can be simulated by the thermal-induced expansion since the volume change caused by wetting in the swelling ground is similar to that by the thermal effect of a material, although the physical mechanism is quite different [26].

The swelling behavior is assumed to be linear, and some strong evidences can be found to support this behavior [27]. The potential linear swelling strain is related to the change in the gravimetric moisture content through a linear expansion coefficient as given below [28]:

$\Delta \varepsilon_{i j}=\beta \delta_{i j} \Delta w$,

where $\Delta \varepsilon_{i j}$ is the swelling strain, $\Delta w$ is the moisture content change variable, $\delta_{i j}$ represents the Kronecker delta, and $\beta$ stands for the one-dimensional linear expansion coefficient which generally depends on the current void ratio and the net isotropic stress level. Due to the assumed isotropy of swelling, the potential swelling strain is one third of the potential volumetric strain.

Rajeev and Kodikara [20] provided an available approach to calculate the linear expansion coefficient, which is given as follows:

$\beta=\frac{\beta^{*} G_{s}}{3(1+e)}$, where $\beta$ is the one-dimensional linear expansion coefficient, $e$ is the void ratio, $G_{s}$ is the specific gravity of soil particle, and $\beta^{*}$ can be calculated using Eq. (6) according to the void ratio-water content diagram, as depicted in Fig. 7.

$\beta^{*}=\frac{\Delta e}{\Delta w G_{s}}$.

According to the thermodynamics theory, the strain induced by the change in temperature is written as:

$\Delta \varepsilon_{i j}=\alpha \delta_{i j} \Delta T$,

where $\alpha$ is the thermal expansion coefficient, and $\Delta T$ represents the temperature change variable.

It is obvious that the mathematical expression of the thermal-induced expansion is consistent with that of the swelling expansion of the soil as it sucks up humility. Combining Eqs. (4) and (7), the thermal expansion coefficient $\alpha$ can be obtained as follows:

$\alpha=\frac{\beta \Delta w}{\Delta T}$.

In the numerical simulation of the swelling ground, the entire formation is assumed to be an isotropic and homogeneous material. In addition, it should be noted that this study did not consider the uneven distribution of the gravimetric moisture content caused by the water seepage in ground, thus, the swelling effect is assumed to be isotropic and homogeneous as well. The 8 -node three dimensional continuum element solid45 was used to simulate the soil mass, its failure behaviors follow the elastic-plastic MohrCoulomb Failure Criterion. The simulation of the swelling soil as it sucks up water was achieved by applying an increasing temperature to the soil element.

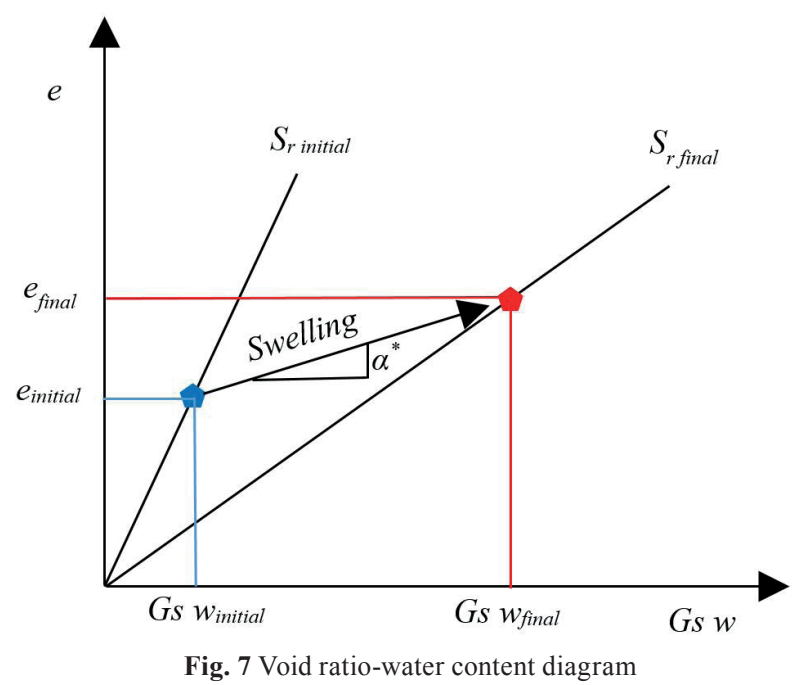

Fig. 7 Void ratio-water content diagram 

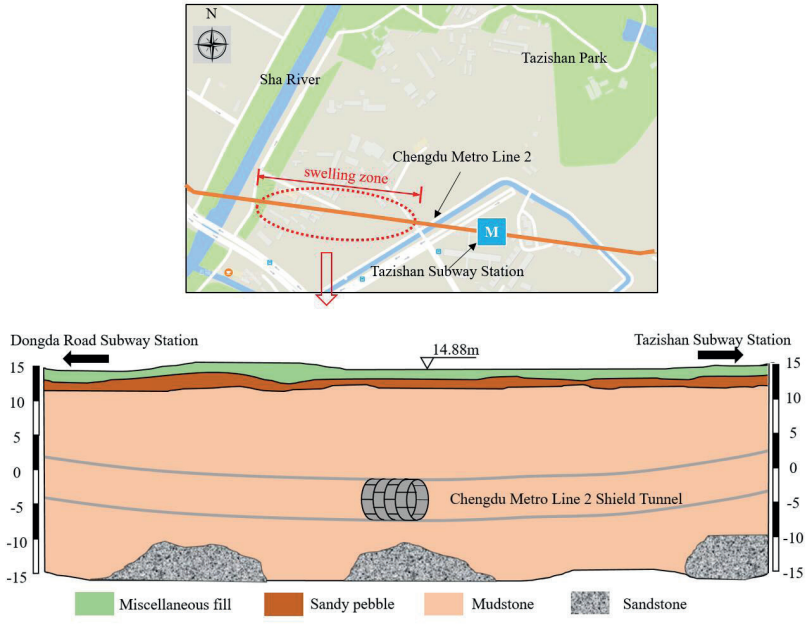

Fig. 8 Plane location and stratigraphic section of the swelling zone

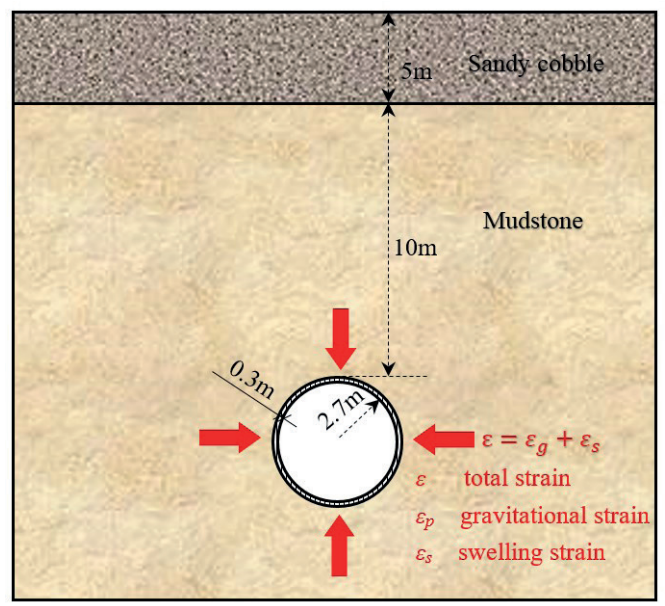

Fig. 9 Calculation model

Taking Chengdu Metro Line 2 as the engineering background, the 3D continuum model of the ground was established. Related ground properties were determined according to the engineering geologic investigation data, which show that the layer that the shield tunnel goes through is mainly highly weathered mudstone with strong swelling characteristics and poor mechanical properties. The plane position of the swelling zone and its vertical stratigraphic section are displayed in Fig. 8. This mudstone layer possesses relatively high strength under the natural water content condition. However, once the moisture content increases, the mudstone shows strong expansion and clear deterioration of the mechanical properties according to some ground sample tests. This behavior caused serious engineering problems during the construction of the shield tunnel in the swelling area, particularly the construction happened to be in the rainy season. It can continuously bring potential threats to the future operation of the shield tunnel.
Therefore, in order to study the internal forces of the tunnel in this case, the authors developed a $3 \mathrm{D}$ continuum-shell-spring model. The diagram of the calculation model is exhibited in Fig. 9. The 3D finite element meshes for the model are shown in Fig. 10. As is shown, the mesh comprising 11150 zones reproduced the ground domain, while 12000 shell elements as well as 2200 spring elements were used to model the shield tunnel linings. Moreover, in order to consider the normal extrusion and tangential friction at the interface between the ground and the tunnel rings, a 3D face-to-face connection was established. The internal MPC-based approach in ANSYS was utilized to achieve the soil-shell assembly by introducing CONTA175 units to the contact surface on the shell element side and TARGE170 units to that on the solid element side, respectively. In addition, the horizontal movements were restrained at the vertical boundaries of the model, and the bottom boundary was restrained against the vertical deformation.

The detailed data concerning the ground properties are given in Table 1. The upper layer of sandy cobble was assumed to be completely non-expansive, and its properties were regarded to be invariable. In addition, the properties of the mudstone swelling layer were marginal and could be assumed to be unaffected with variation of the water content. The one-dimensional linear expansion coefficient $(\beta)$ of the mudstone layer was calculated according to Eqs. (5) and (6), the calculated value of $\beta$ equals $0.24\left(\beta^{*}\right.$ value equals 0.45 ). The thermal expansion coefficient $\alpha$ was obtained on the basis of Eq. (8), being equal to $3.84 \times 10-4$.

Table 1 Detailed ground properties

\begin{tabular}{|c|c|c|}
\hline Layer & Property & Value \\
\hline \multirow{5}{*}{ Sandy cobble } & Unit weight $\left(\mathrm{kN} / \mathrm{m}^{3}\right)$ & 19.00 \\
\hline & Cohesion $(\mathrm{kPa})$ & 21.20 \\
\hline & Internal friction angle $\left(^{\circ}\right)$ & 18.00 \\
\hline & Elastic modulus (Mpa) & 34.50 \\
\hline & Poisson's ratio & 0.20 \\
\hline \multirow{12}{*}{ Mudstone } & Unit weight $\left(\mathrm{kN} / \mathrm{m}^{3}\right)$ & 18.20 \\
\hline & Specific gravity of soil particle & 2.70 \\
\hline & Cohesion $(\mathrm{kPa})$ & 28.50 \\
\hline & Friction angle $\left({ }^{\circ}\right)$ & 17.00 \\
\hline & Elastic modulus (Mpa) & 30.50 \\
\hline & Poisson's ratio & 0.30 \\
\hline & Initial gravimetric water content $(\%)$ & 16.00 \\
\hline & Extreme gravimetric water content $(\%)$ & 36.00 \\
\hline & Initial void ratio & 0.72 \\
\hline & Final void ratio & 0.97 \\
\hline & Initial saturation $(\%)$ & 60.00 \\
\hline & Final saturation $(\%)$ & 100.00 \\
\hline
\end{tabular}




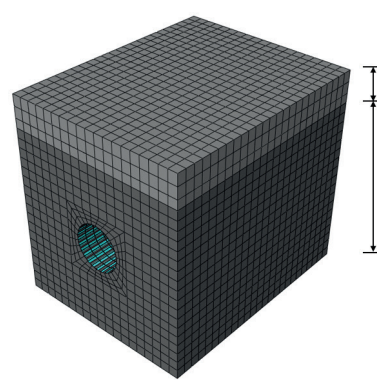

(a)

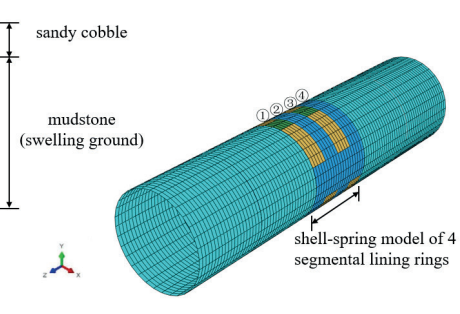

(b)

Fig. 10 Finite element meshes: (a) Continuum-shell-spring model; (b) Shell-spring model of shield tunnel linings

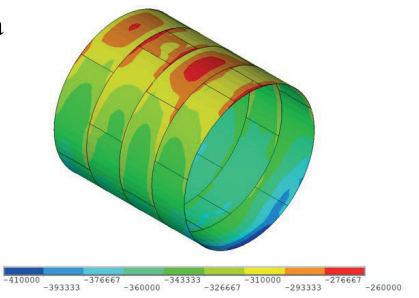

Fig. 11 Internal forces from the constant stiffness model under initial gravity loadings: (a) Axial forces; (b) Bending moments
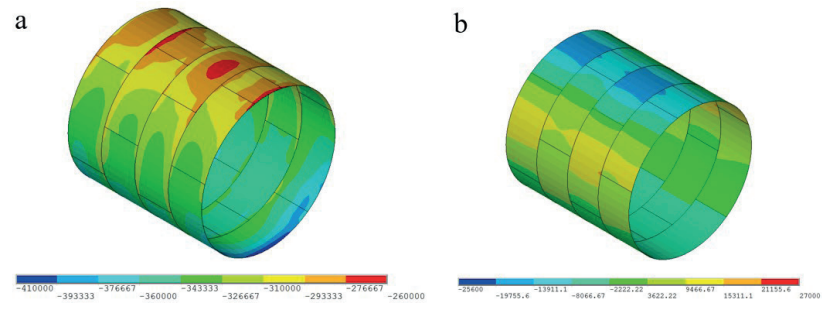

Fig. 12 Internal forces from the proposed iteration model under initial gravity loadings: (a) Axial forces; (b) Bending moments

\section{Results and analysis}

The internal forces of the 4 assembled lining rings were obtained. Fig. 11 and Fig. 12 respectively show the contour figures of internal forces with and without considering the iteration of the non-linear joint bending stiffness under the condition of the initial ground gravity loadings, where no external expansion was applied. As shown in the figures, the $1^{\text {st }}$ lining ring shares similar axial forces and bending moments to that of the $3^{\text {rd }}$ lining ring both in distribution and magnitude due to the fact that the segment arrangements of the two rings are basically the same, while the internal forces of the $2^{\text {nd }}$ ring are quite close to that of the $4^{\text {th }}$ ring. Therefore, in this part, the results of the internal forces of the $2^{\text {nd }}$ and $3^{\text {rd }}$ rings were analyzed.

Fig. 13 and Fig. 14 depict the calculated internal forces in the $2^{\text {nd }}$ and $3^{\text {rd }}$ rings, respectively. It can be seen from Fig. 13 that the segmental lining bears pure compressive axial forces that are distributed along the tunnel perimeter. In addition, the value at the tunnel invert is obviously larger than that at the tunnel crown. And the axial forces on the left and right sides of the lining structure are symmetrically distributed about the midline of the cross section. It is observed from Fig. 13b that the distribution of the bending moments shapes like a "butterfly". The bending moments at the tunnel vault and spandrel reach the maximum negative and positive values, respectively. The values are very small at joints, which are close to zero. Fig. 13 also presents the results of internal forces without considering the iteration of the non-linear bending stiffness. In that case, the stiffness of the bending spring at the circumferential joint model was assumed to be constant (denoted as the constant stiffness model). By comparison between results calculated from the constant stiffness model and the iterative stiffness model, it is found that the influence of the iteration on the axial force is not noteworthy since these two results almost show no big differences. However, the influence on the bending moment is more obvious. The magnitude of the bending moment obtained from the iterative stiffness model is relatively smaller than that obtained from the constant stiffness model, especially at the tunnel vault, invert as well as spandrel locations.

As shown in Fig. 14, axial forces of the $2^{\text {nd }}$ and $3^{\text {rd }}$ rings are roughly at equal levels both in the magnitude and distribution, while the bending moments of these two rings display an obvious difference. However, similar trends between the calculated internal forces from the constant stiffness model and the iterative stiffness model have been observed. Axial forces show no obvious change, while bending moments obtained from the iteration model present a slight decline compared with that from the constant stiffness model.

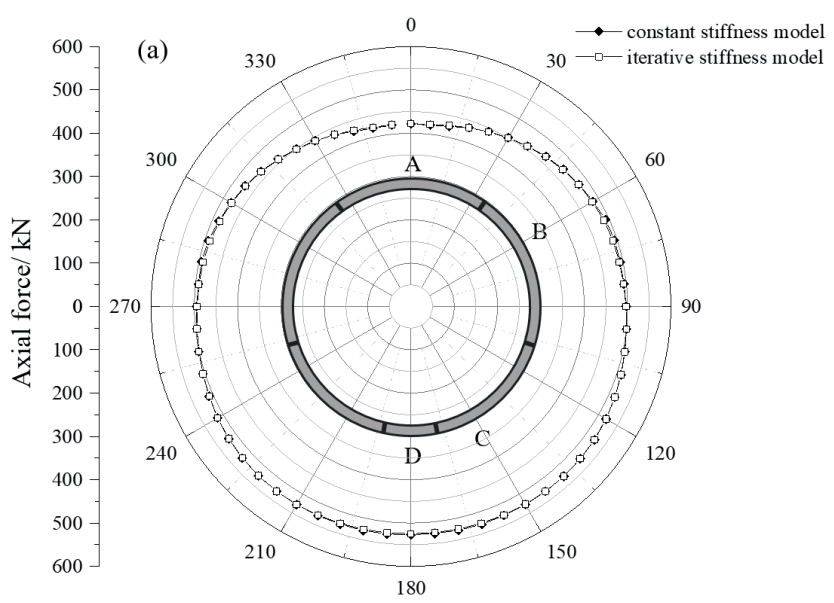

Fig. 13 Internal forces of the $2^{\text {nd }}$ ring under initial gravity loadings: (a) Axial forces; (b) Bending moments 


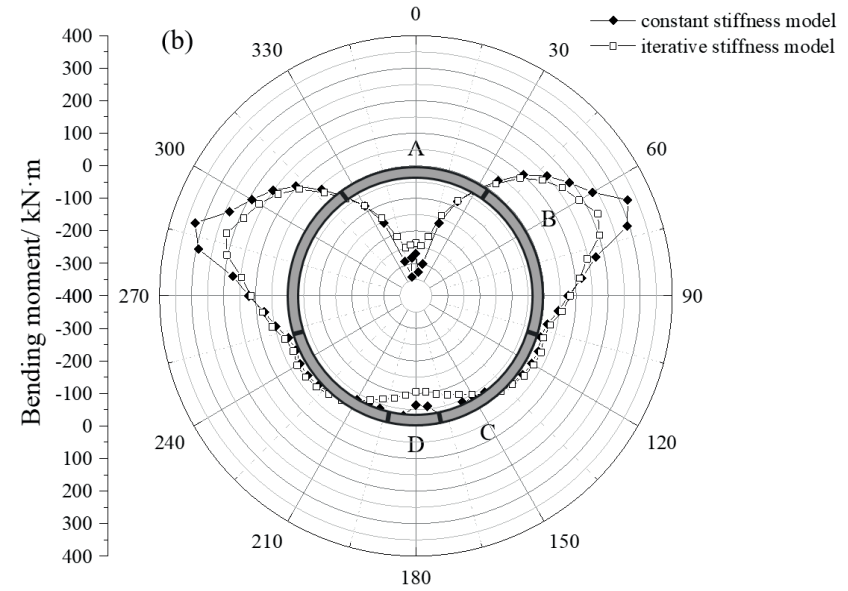

Fig. 14 Internal forces of the $3^{\text {rd }}$ ring under initial gravity loadings:

(a) Axial forces; (b) Bending moments

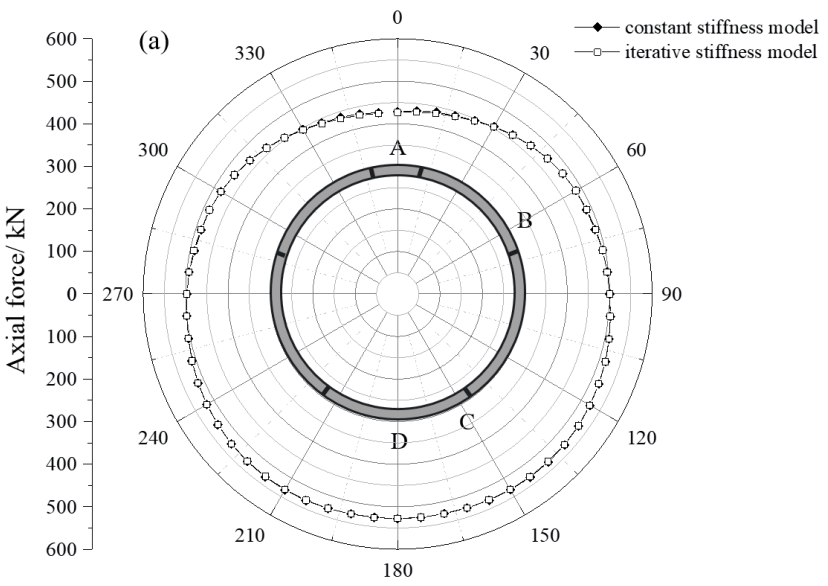

Fig. 15 Internal forces of the 2nd ring under the soil saturated state: (a) Axial forces; (b) Bending moments

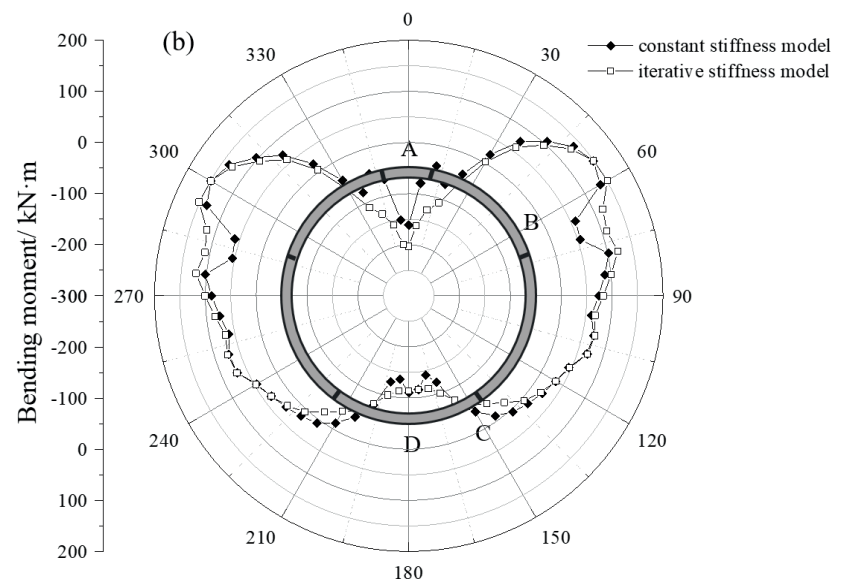

Fig. 16 Internal forces of the 3rd ring under the soil saturated state: (a) Axial forces; (b) Bending moments

Under the circumstance that the external expansion loadings were applied to the tunnel structure apart from ground gravity loadings, it can be observed that the influences of the iteration of the non-linear bending stiffness on the lining internal forces are much more significant. As the ground temperature was set to be $225 \mathrm{~K}$ in calculation, the thermal-induced swelling effect in this case was equivalent to that generated in the moisture content of $36 \%$, the results of the internal forces of the 2nd and 3rd rings were exhibited in Fig. 15 and Fig. 16, respectively. Compared with Figs. 13 and 14, it is seen from Figs. 15 and 16 that the axial forces of the two lining rings both increase dramatically in magnitude while remain almost unchanged in distribution after the additional thermal expansion acts on the tunnel structure. The bending moments show no clear change either in magnitude or distribution, which is mainly attributed to the fact that the ground swelling loadings are distributed approximately evenly along the tunnel perimeter. In addition, it can be concluded that the influence of the iteration is clearly more significant when extra loadings especially swelling loadings are applied to tunnel linings.

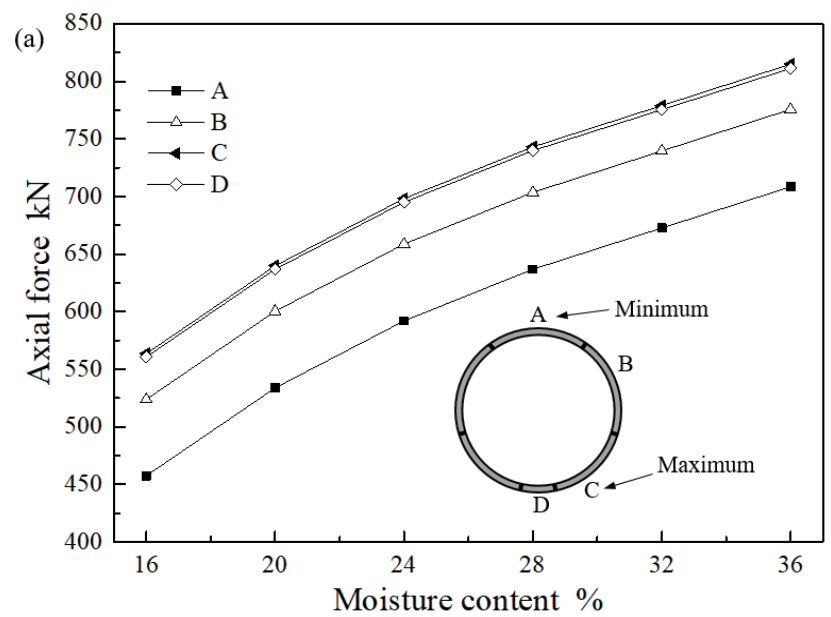

(a) Axial forces

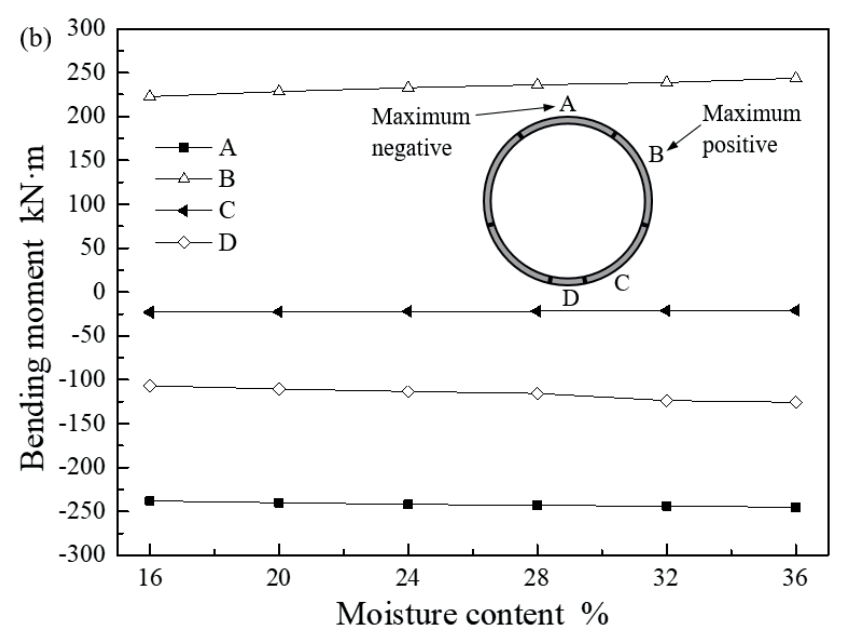

(b) Bending moments

Fig. 17 Trend of internal forces of the $2^{\text {nd }}$ lining ring with the moisture content. 


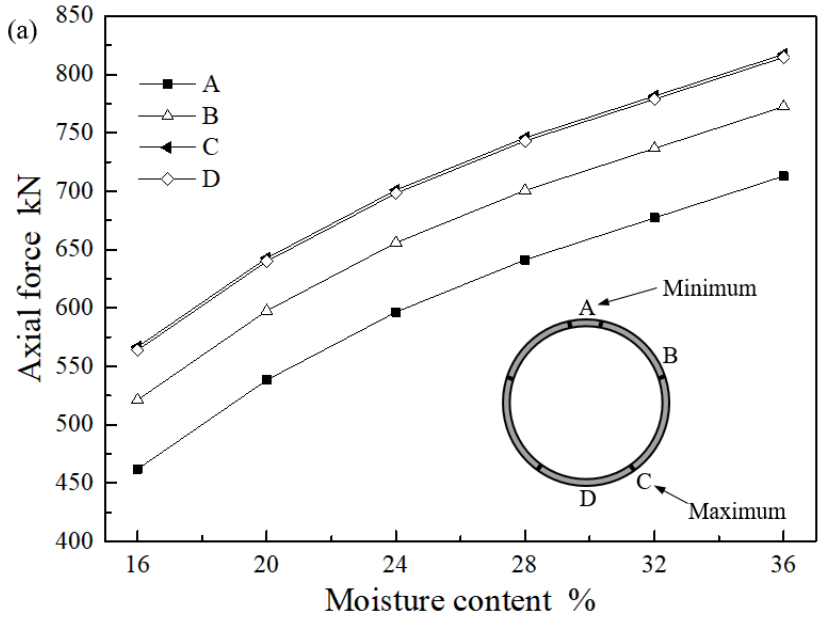

(a) Axial forces

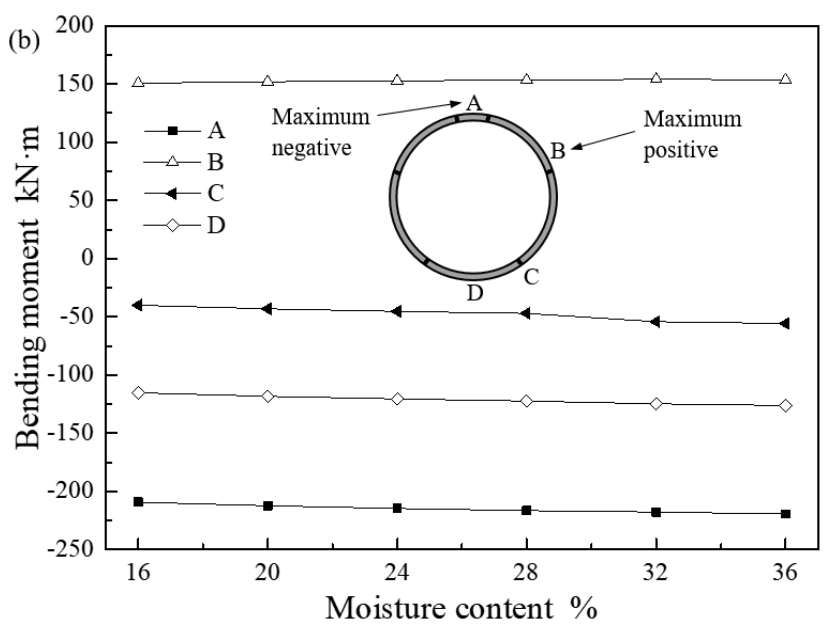

(b) Bending moments

Fig. 18 Trend of internal forces of the $3^{\text {rd }}$ lining ring with the moisture content

Based on the proposed model, the internal forces with variation of the ground water content at different locations in the lining cross section were analyzed. Figs. 17 and 18 demonstrate the trends of the internal forces with the ground humidity at 4 different locations in the cross sections of the $2^{\text {nd }}$ and $3^{\text {rd }}$ rings, respectively.

According to Fig. 17, the value of the axial force at the tunnel vault (location $\mathrm{A}$ ) is the smallest in the $2^{\text {nd }}$ lining ring, while the value at the location $\mathrm{C}$, which is close to the tunnel invert, is the largest. Moreover, the maximum positive and negative values of bending moments locate at the tunnel spandrel (location B) and vault (location A), respectively. In addition, the magnitude of the maximum negative bending moment is larger than that of the maximum positive bending moment. With the growth of the ground moisture content, the axial force gradually goes up with a decreasing growth rate. It reaches to the maximum value when the ground moisture content is at the extreme towards the saturated state, with the moisture content being equal to $36 \%$. Moreover, the axial forces present nearly the same trend with increasing of humidity at these 4 different locations. It is obvious that the increase of the ground moisture content hardly affect the bending moments of the tunnel linings, as shown in Fig. 17b, the bending moments at the 4 different locations basically remain steady with increasing of the moisture content. It should be mentioned that the zero moisture content in the figures does not represent the real ground humidity, which only means that in this situation no any other additional swelling loadings are applied to the tunnel linings.

Compared with results presented in Fig. 17, it can be seen from Fig. 18 that the internal forces of the $3^{\text {rd }}$ lining ring follow a similar trend with the ground moisture content. The maximum values of the axial forces and bending moments are exactly at the same locations as those in the $2^{\text {nd }}$ lining ring, although internal forces of these two lining rings are different in magnitude.

\section{Conclusions and future works}

This research is aimed at the enhancement of the numerical simulation of internal forces of shield tunnel linings subject to the swelling effect. A developed 3D shell-spring model of segmental linings was highlighted, in which the iteration of the non-linear joint bending stiffness was achieved. Furthermore, based on a real engineering case, the proposed model was applied to the FEM calculation and analysis of internal forces of the shield tunnel under the effect of swelling soil. Corresponding to the objective of this research, some conclusions can be drawn as follows:

1. The relationship among the joint bending stiffness, axial force and bending moment was obtained through the numerical simulation using a refined three dimensional continuum model for the segment-joint structure. It is found that the bending moment has a larger influence on the joint bending stiffness than the axial force.

2. By comparison between the results from the proposed iteration model and the constant stiffness model, it is concluded that the nonlinearity of the joint bending stiffness has a significant influence on the magnitude of internal forces but almost no influence on the distribution, especially under swelling loadings. This illustrates that the proposed model has the advantage of avoiding the over-estimation of internal forces of shield tunnel linings. 
3. The swelling effect induced by the growing ground gravimetric moisture content is relatively significant and has a large influence on the lining axial forces. The axial forces of segmental linings in the swelling soil at the extreme saturated state are almost twice as large as that at the initial state. However, in this case, it is revealed that the increase in the ground moisture content hardly affects the bending moment of tunnel linings.

In this paper, the performances of shield tunnel linings under the swelling effect, especially during the tunnel operation period was emphasized. The real-life tunnel excavation and lining installation were not simulated. Based on the proposed model of the tunnel linings, a further numerical simulation considering the step-by-step excavation process will be of great significance. Additionally, the response of lining behaviors to the swelling ground really depends on the homogeneous and isotropic assumption, which can differ a lot from that in the heterogeneous model. Therefore,

\section{References}

[1] Jefferson, I., Rogers, C. D. F. "Collapsible soils" In: Burland, J., Chapman, T., Skinner, H., Brown, M. (eds.) ICE manual of geotechnical engineering. Geotechnical Engineering Principles, 1 st ed., ICE Publishing, London, UK, 2012, pp. 391-407.

[2] Qi, S., Vanapalli, S. K. "Hydro-mechanical coupling effect on surficial layer stability of unsaturated expansive soil slopes", Computers and Geotechnics, 70, pp. 68-82, 2015.

https://doi.org/10.1016/j.compgeo.2015.07.006

[3] Estabragh, A. R., Moghadas, M., Javadi, A. A. "Mechanical behaviour of an expansive clay mixture during cycles of wetting and drying inundated with different quality of water", European Journal of Environmental and Civil Engineering, 19(3), pp. 278-289, 2015. https://doi.org/10.1080/19648189.2014.960098

[4] Reddy, H. P., Prasad, C. R. V., Pillai, R. J. "Swelling of Natural Soil Subjected to Acidic and Alkaline Contamination", Periodica Polytechnica Civil Engineering, 61(3), pp. 611-620, 2017. https://doi.org/10.3311/PPci.8185

[5] Steiner, W. "Swelling rock in tunnels: Rock characterization, effect of horizontal stresses and construction procedures", International Journal of Rock Mechanics and Mining Science \& Geomechanics Abstracts, 30(4), pp. 361-380, 1993.

https://doi.org/10.1016/0148-9062(93)91720-4

[6] Gysel, M. "A contribution to the design of a tunnel lining in swelling rock", Rock Mechanics, 10(1-2), pp. 55-71, 1977. https://doi.org/10.1007/bf01261802

[7] Wittke-Gattermann, P., Wittke, M. "Computation of strains and pressures for tunnels in swelling rocks", In: Underground space for sustainable urban development. Proceedings of the 30th ITA-AITES World Tunnel Congress, Singapore, 2004, pp. 422-423. https://doi.org/10.1016/j.tust.2004.02.040

[8] Barla, M. "Numerical simulation of the swelling behavior around tunnels based on special triaxial tests", Tunnelling and Underground Space Technology, 23(5), pp. 508-521, 2008. https://doi.org/10.1016/j.tust.2007.09.002 a more reasonable and refined soil model needs to be established in future works, especially taking consideration of the uneven swelling. Moreover, further researches on this topic through the physical model experiment and related in-situ monitoring are of great significance for the improvement and validation of the proposed model. All these mentioned aspects will contribute to a better understanding of structural behaviors of shield tunnel linings in the swelling ground.

\section{Acknowledgement}

The authors gratefully acknowledge financial support for this research provided by the National Key R \& D Program of China (2016YFC0802205), and financial supports from the National Science Foundation of China $(51678500,51878573)$ are also gratefully acknowledged. In addition, the author Chuan Zhang's research at University of Houston is sponsored by the China Scholarship Council (CSC NO.201707000109).

[9] Anagnostou, G. "A model for swelling rock in tunnelling", Rock Mechanics and Rock Engineering, 26(4), pp. 307-331, 1993. https://doi.org/10.1007/bf01027115

[10] Vu, H. Q., Fredlund, D. G. "The prediction of one-, two-, and threedimensional heave in expansive soils", Canadian Geotechnical Journal, 41(4), pp. 713-737, 2004. https://doi.org/10.1139/t04-023

[11] Tu, H., Vanapalli, S. K. "Prediction of the variation of swelling pressure and one-dimensional heave of expansive soils with respect to suction using the soil-water retention curve as a tool", Canadian Geotechnical Journal, 53(8), pp. 1213-1234, 2016. https://doi.org/10.1139/cgj-2015-0222

[12] Parsapour, D., Fahimifar, A. "Prediction of swelling rocks strain in tunneling", Geotectonics, 50(3), pp. 336-346, 2016. https://doi.org/10.1134/s0016852116030092

[13] Wang, J., Liu, J., Liu, X., Jiang, Y., Liu, X. "In-site experiments on the swelling characteristics of a shield tunnel in expansive clay: A case study", KSCE Journal of Civil Engineering, 21(3), pp. 976-986, 2017. https://doi.org/10.1007/s12205-016-1333-4

[14] Fang, Y., He, C., Qi, C., Zhang, M. "Structural Internal Force of Shield Tunnel in Expansive Soil Underlying Sandy Pebble Layer", Journal of Southwest Jiaotong University, 49(3), pp. 386-392, 2014. (in Chinese) https://doi.org/10.3969/j.issn.0258-2724.2014.03.003

[15] Seifabad, M. C., Sadrnejad, S. A., Ebrahimi, D. "A Study of Swelling Behaviour in a Tunnel Using Finite Element Methods", Periodica Polytechnica Civil Engineering, 59(2), pp. 103-107, 2015. https://doi.org/10.3311/PPci.7538

[16] Winkler, B., Hofstetter, G., Lehar, H. "Application of a constitutive model for concrete to the analysis of a precast segmental tunnel lining", International Journal for Numerical and Analytical Methods in Geomechanics, 28(7-8), pp. 797-819, 2004. https://doi.org/10.1002/nag.362 
[17] Yan, Q., Li, B., Geng, P., Chen, C., He, C., Yang, W. "Dynamic response of a double-lined shield tunnel to train impact loads", Tunnelling and Underground Space Technology, 53, pp. 33-45, 2016. https://doi.org/10.1016/j.tust.2015.12.004

[18] Yan, Q., Deng, Z., Zhang, Y., Yang, W. "Failure Characteristics of Joint Bolts in Shield Tunnels Subjected to Impact Loads from a Derailed Train", Shock and Vibration, Article ID 2829783, 2017. https://doi.org/10.1155/2017/2829783

[19] Yan, Q., Xu, Y., Zhang, W., Geng, P., Yang, W. "Numerical analysis of the cracking and failure behaviors of segmental lining structure of an underwater shield tunnel subjected to a derailed high-speed train impact", Tunnelling and Underground Space Technology, 72, pp. 41-54, 2018.

https://doi.org/10.1016/j.tust.2017.11.002

[20] Rajeev, P., Kodikara, J. "Numerical analysis of an experimental pipe buried in swelling soil", Computers and Geotechnics, 38(7), pp. 897-904, 2011. https://doi.org/10.1016/j.compgeo.2011.06.005

[21] Cavalaro, S. H. P., Aguado, A. "Packer behavior under simple and coupled stresses", Tunnelling and Underground Space Technology, 28, pp. 159-173, 2012. https://doi.org/10.1016/j.tust.2011.10.008

[22] Do, N.-A., Dias, D., Oreste, P., Djeran-Maigre, I. "2D numerical investigation of segmental tunnel lining behavior", Tunnelling and Underground Space Technology, 37, pp. 115-127, 2013

https://doi.org/10.1016/j.tust.2013.03.008
[23] Feng, K., He, C., Xiao, M. "Bending tests of segment joint with complex interface for shield tunnel under high axial pressure", China Civil Engineering Journal, 49(8), pp. 99-110, 2016. (in Chinese) https://doi.org/10.15951/j.tmgcxb.2016.08.012

[24] Briaud, J.-L., Zhang, X., Moon, S. "Shrink Test-Water Content Method for Shrink and Swell Predictions", Journal of Geotechnical and Geoenvironmental Engineering, 129(7), pp. 590-600, 2016. https://doi.org/10.1061/(asce)1090-0241(2003)129:7(590)

[25] Gould, S. J. F., Kodikara, J., Rajeev, P., Zhao, X. L., Burn, S. "A void ratio - water content - net stress model for environmentally stabilized expansive soils", Canadian Geotechnical Journal, 48(6), pp. 867-877, 2011. https://doi.org/10.1139/t10-108

[26] Tang, S. B., Tang, C. A. "Numerical studies on tunnel floor heave in swelling ground under humid conditions", International Journal of Rock Mechanics and Mining Sciences, 55, pp. 139-150, 2012. https://doi.org/10.1016/j.ijrmms.2012.07.007

[27] Sivakumar, V., Tan, W. C., Murray, E. J., McKinley, J. D. "Wetting, drying and compression characteristics of compacted clay", Géotechnique, 56(1), pp. 57-62, 2006. https://doi.org/10.1680/geot.2006.56.1.57

[28] Kodikara, J. K., Choi, X. "A Simplified Analytical Model for Desiccation Cracking of Clay Layers in Laboratory Tests", presented at Proceedings of the Fourth International Conference on Unsaturated Soils, UNSAT 2006, Carefree, AZ, USA, April 2-6, 2006. https://doi.org/10.1061/40802(189)218

\section{Appendix 1: Determination of the bolt pre-tightening force}

The deformation of the joint bolt subject to the external loading can be calculated as follows:

$\Delta l_{1}=\frac{Q}{K_{b}}=\frac{Q l}{E A}$.

The deformation of the segment concrete connected through the joint bolt can be obtained as follows:

$$
\Delta l_{2}=\frac{Q}{K_{c}},
$$

where $Q$ denotes the external loading applied to the bolt, $l$ and $A$ represent the length and sectional area of the bolt component, respectively, $E$ is the elastic modulus of the bolt, $K_{b}$ and $K_{c}$ are the stiffness of the bolt and concrete, respectively.

The total deformation of the bolt and segment concrete is as follows:

$$
\Delta l=\Delta l_{1}+\Delta l_{2} .
$$

In addition, the deformation induced by the temperature decrease can be expressed as follows:
$\Delta l=a \Delta T l$,

$\Delta T=T_{0}-T_{c}$,

where $a$ is the expansion coefficient of the bolt, $\Delta T$ represents the temperature variable of the bolt, $T_{0}$ and $T_{c}$ denote the initial and current temperatures, respectively.

Let $T_{0}$ equals zero, then there is:

$T_{c}=-\frac{\Delta l}{\alpha \cdot l}$.

Therefore, based on the above equations, the bolt pre-tightening loading can be equivalent to the temperature variable. The initial temperature is assumed to be $273.0 \mathrm{~K}$, and the bolt temperature is set to reduce by $100 \mathrm{~K}$. Through the numerical calculation, the axial stress of the joint bolt under different temperature strain was calculated, and the bolt pre-tightening force was further obtained. The results shows that the bolt pre-tightening force presents a linear relationship with the temperature strain. When the axial strain induced by the temperature change is 0.0012 , the pre-tightening force exactly equals $100 \mathrm{kN}$. 